\title{
Just who do Canadian journalists think they are? Political role conceptions in global and historical perspective
}

\author{
Heather Rollwagen \\ Department of Sociology \\ Ryerson University \\ 350 Victoria Street \\ Toronto ON M5B 2K3 \\ Ivor Shapiro \\ School of Journalism \\ Ryerson University \\ 350 Victoria Street \\ Toronto ON M5B 2K3 \\ Geneviève Bonin-Labelle \\ Department of Communication \\ University of Ottawa \\ Desmarais Building \\ 55 Laurier Avenue East \\ Ottawa ON K1N 6N5 \\ Lindsay Fitzgerald \\ Independent multimedia journalist \\ No institutional address \\ Lauriane Tremblay \\ Département d'information et communication \\ Pavillon Louis-Jacques-Casault \\ Université Laval \\ 1055, avenue du Séminaire \\ Québec, QC G1V 0A6
}

The authors wish to thank Dr. David Pritchard, who generously provided feedback on earlier versions of this paper, as well as the CJPS reviewers for their constructive ideas and helpful comments. We also acknowledge the support of the SSHRC Insight Grant program. 


\begin{abstract}
In view of the robust link often inferred between autonomous journalism and the strength of a society's democratic institutions, and against the background of current challenges to journalists' traditional roles as purveyors of timely and independent information, we interviewed 352 Canadian journalists about their social and political roles and the influences on their news choices. Comparison of their responses against an international dataset $(N=27,567)$ suggests that Canadian journalists place greater value on detached monitorial roles and claim relative autonomy from commercial and other influences on their work. Further, in comparing these findings to an influential panel study from 1999 to 2003, we conclude that the Canadian journalists' "credo," focused on neutral reporting and oriented more to perceived public interest than to business or audience interests, remains surprisingly intact despite contemporary pressures on news forms and business models. This professed neutrality is mitigated by a desire to promote diversity and tolerance.
\end{abstract}


Truisms abound concerning the link between healthy journalism and functional democracies. "Democracy dies in darkness," runs the Washington Post's motto, while that of the Canadian Journalism Foundation is: “As journalism goes, so goes democracy.” Most recently, the federal government defended its November, 2018 proposal of tax measures to support news production by stating: "A strong and independent news media is crucial to a well-functioning democracy." (Government of Canada 2018) At least since the time of Walter Lippman, the quality of news coverage has been linked explicitly to informed public opinion, political agendas and policymaking, a relationship whose mechanics continue to be probed and debated. (McCombs 2017; Ardıç, Annema, and van Wee 2015; Strömbäck 2008; Melenhorst 2015; Wolfe, Jones, and Baumgartner 2013; Tan and Weaver 2009; Kim and McCombs 2007; Davis 2007)

Recent years, however, have witnessed dramatic alterations in the global information ecosystem. People no longer need to rely on the news media for the formation, debate and expression of opinions; public information is increasingly available directly to anyone, and anyone can easily publish their own opinions or launch a new platform for facts, alleged facts and opinion, almost instantly and with no capital investment. Although information must still pass through definable "gates" and "channels" to travel from private domains to publics, and although news workers are still often involved in these journeys, the processes have become much more complex than in the 20th Century, and less reliant on journalists' decisions about what constitutes “news.” (Shoemaker and Vos, 2008, 128-130.)

Despite these transformations, Canadians continue to profess significantly more confidence in the trustworthiness of news created by legacy news organizations than do citizens in many other countries, and established media brands continue to be the go-to source for news in this country (Greenspon 2017, 42-43; Mitchell et al. 2018, 5; Newman 2018, 118-19; Ekos 
Research Associates 2018). It therefore seems reasonable to assume that many (not all) citizens' understanding of many (not all) politically relevant facts, and of the range of available opinions on public policy, continue to be shaped to some significant degree by journalists' choices about newsworthiness, sources and story-telling.

Almost needless to say, these news choices are made under the influence of a wide range of factors. The list of influences that have been suggested by theorists, critics and observers includes, to name a few, several pertaining to the evolution of news routines and cultures; professional assumptions about what constitutes news and how it is most effectively conveyed; the economic and ideological systems within which journalists operate; the ease of reliance on elite sources versus the resource demands of original research; media owners' financially oriented interest in legitimating the status quo and delegitimating the Left; and the regulations and expectations attached to publicly owned or licensed broadcasters. (See, for example, Tuchman 1978, 209-216; Schudson 2002, 123-127; Milliband 1969, 221-224; Shoemaker and Reese 2014, 64-202; Hackett 2002, 4-7) The range and potential combinations of these influences can amount to subtle, almost subversive impediments to journalists' freedom to live up to their ideals of autonomy, no matter how sincerely these ideals may be held. As Hackett suggested:

...[T]he most important form of external influence upon journalism is not explicit and occasional interventions (like an advertiser trying to kill a story, or a source pressing for favourable spin), but rather the long-term re-structuring of the ground rules and routines which shape (relatively autonomous) journalism on a workaday basis. (Hackett 2006, 7) Those everyday "ground rules and routines" now include increasing attention to minuteby-minute audience analytics, with demonstrated influence on news judgment. (Tandoc and 
Thomas 2015; Vu 2013; Welbers et al. 2015) In this pressure-cooker of external influences, journalists' own role conceptions - and particularly the extent to which they may understand themselves as having a differentiated professional role from merely pleasing their employers or audiences - may be seen as a necessary, but perhaps increasingly unlikely, predictor of quality in news content. As Schudson put it:

...[T]he desire of journalists to produce news according to their own best judgment can be a significant constraint on commercial motives. It does not always triumph, of course, but as long as journalists are needed to report the news, journalists will have a measure of power in media organizations. They may maintain this power through their vigilance or they may lose it through their fears. (Schudson, 2002, 123)

How strong, then, are journalists' collective commitment to a sense of socio-political mission, and how potently does that professional mandate constrain the forces inhibiting that mission's fulfilment? These are the driving questions behind our investigation of Canadian journalists' role conceptions and the influences they perceive upon their work.

\section{Previous research}

Social psychologists have demonstrated a robust connection between what people say they value, on the one hand, and how they behave, on the other. (Norman T. Feather 1988; Bardi and Schwartz 2003) Acting in accordance with one's values provides psychological rewards in the form of a sense of consistency. (Rokeach 1973; N. T. Feather 1995) This general truth also applies to a relationship between journalists' values and their choices at work - a relationship that may be assumed to play out differently in diverse news-making cultures. (Hanitzsch 2007; Donsbach 2004; Patterson and Donsbach 1996). These cultures are known to vary significantly 
amongst nations and global regions (see, for example, Ahva et al. 2017; Hanusch 2009; Preston 2008; Weaver and Willnat 2012), but in economically developed democracies, the idea of a "socially responsible" press that holds special freedoms "in trust for the entire population”(Siebert et al., 1956, 101) may still broadly be recognized as dominant. Important distinctions amongst these democracies' media systems have been theorized, such as the partisan-pluralist tradition rooted in southern Europe and the aspirations toward independent reporting associated with the largely Anglo-American tradition of "liberal" media systems (Hallin and Mancini 2004). Previous work by the present authors, together with colleagues in Belgium and Switzerland, investigated the extent to which the legacies of the latter two media systems might be associated today with differing role-perceptions on the part of journalists in anglophone majorities and francophone minorities. (Bonin et al. 2017)

To map the role conceptions of 1,800 journalists in 18 countries in the precursor of the current Worlds of Journalism Study (WJS), Hanitzsch used cluster analysis to posit four milieu. "Detached watchdogs" focus on informing citizens and monitoring government and business; “critical change agents" seek an impact on social change; and "populist disseminators" work to attract and engage audiences with ideologically neutral purpose. A fourth type, "opportunist facilitators," occurs mostly in more authoritarian contexts. (Hanitzsch 2011) Such distinctions of emphasis in terms of role have often been associated with journalists' differing views, in particular countries and world regions, on relative support for objectivist versus interventionist approaches to political roles. (Hanitzsch et al. 2011; Donsbach and Klett 1993) More recently, Lauerer and Hanitzsch (forthcoming) employed a formative approach to constructing indexes of role orientations and perceived influences using the current WJS global data set. They propose four broad roles orientations: the monitorial role, the interventionist role, the collaborative role, 
and the accommodative role. Further, they propose six dimensions of perceived influences: political/government influences; organizational influences; procedural influences; economic influences; and personal/social influences. The construction of these broad categories is thought to capture the diversity in journalistic cultures that exist around the world.

The first comprehensive study of Canadian journalists' role conceptions, fielded by Pritchard and Sauvageau in 1996, found evidence of a broadly shared Canadian journalists' "credo" expressed in five professional values: accuracy, disseminating news quickly, giving ordinary people the chance to express their views, investigating government, and providing analysis of complex problems. The study showed considerable similarity in the professional values of journalists at French-language and English-language news organizations, casting doubt on assumptions that English-language journalists might be more oriented toward facts and French-language journalists toward opinion. (Pritchard and Sauvageau 1999, 108-11). However, this Canadian "credo" has yet to be situated in a more global perspective. To what degree do these conceptions differ from journalists globally or, more specifically, from those within the "liberal" media system that, as classified by Hallin and Mancini, 2004, generally aligns with anglophone-dominant developed countries? Thanks to the ongoing Worlds of Journalism Study, we are now in a position to begin answering these questions by comparing Canadian journalists' responses to those of peers elsewhere.

There is also reason to probe the degree, if any, to which the Canadian "credo" might have survived the past two decades of profound change. When a panel of approximately 40 per cent of Pritchard and Sauvageau's (1999) respondents were re-surveyed seven years later, support for the journalists' "credo" had eroded somewhat among journalists at English-language media, but not among those at French-language media. (Pritchard, Brewer, and Sauvageau 2005) 
Perhaps significantly, the period covered by those surveys had seen a rise in Internet usage and consolidations in Canadian news-media ownership (Soderlund et al. 2012), but those changes were mere foreshadows of the more landscape-altering birth of social media with Facebook's launch in 2004, and, the following year, Google's mastery of the personalized search algorithm. (Greenspon 2007, 99) With journalists now facing stiffer competition from informal media than from other traditional news sources, measures of achievement became more diverse, and the availability of real-time audience analytics has heightened journalists' awareness of the popularity, versus social importance, of their coverage. (Bruns 2005; Peer and Ksiazek 2011; Tandoc 2014; Thompson 2014; Lee and Tandoc 2017).

The impacts of these changes on the news business were dramatic. As advertising revenue, formerly earned in return for news organizations' investment, began flowing inexorably to Google and Facebook, legacy companies' profitability fell precipitously. The sheer number of full-time employed journalists shrank in lockstep, and consumers' exposure to news became increasingly selective and personalized. (Fry 2017; Greenspon 2017; Drohan 2016)

Given these harsh realities of the news business today, it seems reasonable to expect a rise in the relative importance attached by today's journalists to luring, finding and satisfying audiences, as compared with a more monitorial role, by which we mean one that involves independently describing, analyzing and interpreting matters of public interest. The time is therefore ripe to return to the question of who today's Canadian journalists are, or at least who they think they are, in terms of their politically relevant role conceptions and the extent to which they claim personal autonomy in deciding on stories, story angles, sources, and narrative frames vis à vis social and corporate influences upon their day-to-day work. These fluctuating influences may include (in addition to the wider national and cultural contexts noted above) organizational factors including 
news routines, limits on time and other resources, audience-research data, relationships with sources, employers' business interests, the views of friends and family, and public-relations efforts, amongst others. (Hanitzsch et al. 2010)

Our study therefore seeks to understand Canadian journalists' perspectives of their social purpose and the influences on their work within both global and historic contexts, through investigating two research questions. First, what conceptions do Canadian journalists have of the political role of the news media, and to what extent are Canadian journalists' conceptions of the political role of the news media distinct from those of journalists in other countries? Based on the work of Hallin and Mancini (2004) and Hanitzsch et al. (2011), we hypothesized that Canadian journalists would identify with a more liberal and detached approach compared to the global population, but that any such difference would shrink when compared with countries with similar political, economic, and cultural systems. Second, how has the Canadian journalists' "credo," as identified by Pritchard and colleagues (2005), changed (if at all) since the end of the twentieth century? Given the current economic pressures faced by news organizations in general, as described above, we hypothesized that journalists' role conceptions would have shifted in recent years to attach less importance to the normative monitorial credo, and greater importance to audience gratification.

\section{Method}

The data used in this analysis were collected for the Worlds of Journalism Study (WJS) - a collaborative research effort comprising 67 countries with a mandate to "better understand the worldviews and changes that are taking place in the professional orientations of journalists, the conditions and limitations under which journalists operate, and the social functions of journalism 
in a changing world" (Worlds of Journalism 2017). Each participating country collected data using a standardized set of questions and provided results to an eventual global data set with 27,567 cases. The specific methods of data collection varied somewhat by country, but all data collected met minimum standards set out by WJS methodology protocols. Given the focus on Canadian journalists for this analysis, we will describe here the procedures used within Canada.

In accordance with the WJS guidelines, a stratified random sampling approach was used to reflect the nature of journalistic employment in Canada. Approximately 15 percent of the sample was selected from among freelance journalists. The sample of freelance journalists was drawn from a list of self-identified journalists registered with the Professional Writers Association of Canada. The remaining sample was selected from among salaried journalists by first stratifying news organizations by size (small, medium and large), randomly sampling news organizations from within each of the strata, and then randomly sampling between 2 and 5 journalists from within each of these organizations, depending on the size classification. Sampling was also adjusted to ensure inclusion of sufficient journalists working in French (the final proportion was 31.5\%), with all other respondents working in English. The sample included journalists working within publicly and privately owned media types (newspapers, magazines, TV, radio, online and agencies) with national, regional and local reach, and both "quality"/broadsheet and popular/tabloid audience orientation. Telephone interviews were conducted between 2014 and 2016. The response rate was $22 \%$, yielding a sample size of 352 . This response rate is as expected, given that participation in this study was voluntary. The identity of all research participants was kept confidential, and data maintained in a secure manner.

Given the research questions specified above, this report focuses on those responses to the WJS questionnaire that shed light on journalists' politically relevant role conceptions and the 
influences on their work. Political role conceptions are determined through a self-reported measure of the relative importance of a range of occupational roles. Respondents rated the importance of 21 potential roles on five-point scales (from extremely important to unimportant). Perceived influences on journalistic work were examined by asking about the relative influence of 27 possible influences (also on a five-point scale, from extremely influential to not influential). All questions regarding roles and influences that are included in the WJS questionnaire are included in this analysis. This questionnaire was constructed with the input from research teams in all 67 participating countries, and therefore reflects the breadth of possibility with respect to journalistic roles and influences. Our results provide the mean scores for each item. Within the tables, these items are organized thematically, according to the conceptualization proposed by Lauerer and Hanitzsch (forthcoming) mentioned earlier in this paper.

To situate Canadian journalists comprehensively in the global context, we made comparisons against four comparator groups of WJS-participant countries. We first compare Canadian journalists to all of the other 66 participating countries to offer a global comparison. Second, given our desire to compare Canadian journalists to those from countries with similar political and economic systems, we compare Canadian journalists to other "developed countries" as defined by the United Nations World Economic Situation and Prospects classification (United Nations 2018). Third, recognizing the way in which language may relate to a journalistic culture, we offer a third comparison group that includes those developed countries for which English is the dominant language (Australia, Ireland, New Zealand, the United Kingdom and the United States). Lastly, we compare Canadian journalists to the United States alone, given both the strong cultural and economic connections between the two countries overall and, specifically, 
Hallin and Mancini's (2004) assumption of a strong similarity between the two countries' media systems.

To make these comparisons, analysis of variance tests were used to determine if the differences between the mean scores were statistically significant $(\mathrm{p}<0.05)$. The means were calculated based on individual responses, and not on averaged country mean scores. Thus, while all participating countries met the minimum standards in terms of sample sizes, some countries contributed a greater number of journalists to the overall data set than others. The average sample size was $411.45(\mathrm{sd}=211.78)$ and the median sample size was 371 . The minimum sample size was 90 (Bhutan), and the largest was 1362 (Denmark). 75 percent of the participating countries contributed samples ranging from 200 to 600 journalists, and no single country contributed more than $5 \%$ to the total sample.

To answer the second research question, which investigates the possibility of changes to the Canadian "credo" since the end of the twentieth century, we were obliged to employ a more general approach. The questions asked by Pritchard, Brewer, and Sauvageau (2005) differed in several respects from our internationally standardized questionnaire; their respondents were offered 13 role statements compared with 21 adopted by global consensus for the WJS questionnaire. Nevertheless, we were able to identify seven role statements that were sufficiently similar between the two studies to be paired up. We then examined the relative rank of importance accorded to these paired roles in each study. The seven pairings may be broadly summarized (in order of the mean scores by 1996 respondents) as: accurate reporting on public affairs; analyzing and interpreting current affairs; allowing people to express their views; scrutinizing business activities; providing news of interest to the widest audience; providing entertainment and relaxation; and influencing public opinion. While there are notable challenges 
and limitations in comparing data that were collected for different purposes and with variations in methodology, we determined that comparing the rankings of these paired statements in 1996 versus 2014-16 could offer high-level insight on the extent to which the Canadian journalists' "credo" had either endured or diminished over the raucous intervening period in news-media development.

\section{Results}

To provide some context for the population of those working in professional journalism, Table 1 presents general demographic, employment and political characteristics. Journalists, both in Canada and elsewhere, are slightly more likely to be male than female. Canadian journalists are more likely than global peers to have a bachelor's or college degree, although there are no substantial differences with respect to their achievement of graduate degrees in journalism. The Canadians are slightly older, at an average of 44.51 years, than the global mean of 39.00 .

Politically, the data on self-described political stance (measured from 0 , representing the left end of the political spectrum, to 10, on the right) suggest that Canadian journalists lean, on average, slightly more left of centre (with a mean score of 4.22) than either the global sample (4.47) or even that of English-speaking developed countries (4.44). However, it is noteworthy that $60.5 \%$ of journalists who stated their political stance identified themselves in the centre-most range of 4,5 or 6 .

Further, when asked how they voted in the most recent federal election (data not presented in Table 1), 27.1\% of the Canadian journalists reported voting for the Liberal Party, 23.7\% for the New Democratic Party, $8.5 \%$ for the Conservative Party, and $13.5 \%$ for other 
parties (including the Green Party and the Bloc Quebecois), with 4.8\% reporting that they did not vote. Important, however, is that a little over $22 \%$ of the sample did not respond to this question.

(For about 100 respondents, this "most recent" election was in 2011, while others were

interviewed after the 2015 election; the fluctuating popularity or otherwise of particular political

leaders may have distorted the apparently lopsided spread of party preferences.)

Table 1: Demographic and employment profile of Canadian journalists

\begin{tabular}{|c|c|c|c|c|c|}
\hline & $\begin{array}{l}\text { Canada } \\
(\mathrm{N}=352)\end{array}$ & $\begin{array}{c}\text { Global } \\
\text { (excluding } \\
\text { Canada) } \\
(\mathrm{N}=27,215)\end{array}$ & $\begin{array}{c}\text { Other } \\
\text { developed } \\
\text { countries } \\
(\mathrm{N}=14,105)\end{array}$ & $\begin{array}{l}\text { Other English- } \\
\text { speaking } \\
\text { developed } \\
\text { countries } \\
(\mathrm{N}=2,562) \\
\end{array}$ & $\begin{array}{c}\text { USA } \\
(\mathrm{N}=414)\end{array}$ \\
\hline \multicolumn{6}{|l|}{ Gender } \\
\hline \begin{tabular}{l|l} 
Female \\
\end{tabular} & $43.5 \%$ & $42.5 \%$ & $44.0 \%$ & $45.5 \%$ & $27.1 \% *$ \\
\hline Male & $56.5 \%$ & $57.5 \%$ & $56.0 \%$ & $54.5 \%$ & $72.9 \% *$ \\
\hline \multicolumn{6}{|l|}{ Age } \\
\hline (mean / std. dev) & $44.51(11.88)$ & $39.00(11.54)^{*}$ & $42.12(11.57)^{*}$ & $42.10(12.50)^{*}$ & $46.91(11.92)^{*}$ \\
\hline \multicolumn{6}{|l|}{ Education } \\
\hline \begin{tabular}{l|l} 
Less than high school \\
\end{tabular} & $0.3 \%$ & $1.0 \% *$ & $1.3 \% *$ & $0.6 \% *$ & $0 \% *$ \\
\hline High school complete & $4.3 \%$ & $8.2 \% *$ & $9.3 \% *$ & $6.9 \% *$ & $1.5 \% *$ \\
\hline Some university & $2.0 \%$ & $6.7 \% *$ & $7.6 \% *$ & $6.2 \% *$ & $4.8 \% *$ \\
\hline College/Bachelor's & $64.9 \%$ & $53.6 \% *$ & $46.8 \% *$ & $64.5 \% *$ & $72.6 \% *$ \\
\hline Master's Degree & $27.4 \%$ & $28.7 \% *$ & $33.1 \% *$ & $20.9 \% *$ & $20.8 \% *$ \\
\hline Doctorate & $1.1 \%$ & $1.8 \% *$ & $1.8 \% *$ & $0.8 \% *$ & $0.2 \% *$ \\
\hline \multicolumn{6}{|l|}{ Political Stance: 1 to 10} \\
\hline \begin{tabular}{l|l} 
& $($ mean / std. dev $)$ \\
\end{tabular} & $4.22(1.66)$ & $4.47(2.04)^{*}$ & $4.44(1.99)$ & $4.44(1.61)^{*}$ & $4.76(1.51)^{*}$ \\
\hline \multicolumn{6}{|l|}{ Employment 1} \\
\hline \begin{tabular}{l|l} 
& Full-time \\
\end{tabular} & $78.1 \%$ & $78.9 \% *$ & $77.7 \% *$ & $85.0 \% *$ & $98.8 \% *$ \\
\hline Part-time & $3.4 \%$ & $9.9 \% *$ & $8.8 \% *$ & $5.5 \% *$ & $0.2 \% *$ \\
\hline Freelance & $17.0 \%$ & $9.8 \% *$ & $12.2 \% *$ & $8.2 \% *$ & $0.7 \% *$ \\
\hline \begin{tabular}{l|l} 
Other \\
\end{tabular} & $1.4 \%$ & $1.4 \% *$ & $1.3 \% *$ & $1.4 \% *$ & $0.2 \% *$ \\
\hline \multicolumn{6}{|l|}{ Union Membership } \\
\hline Member & $56.4 \%$ & $50.8 \% *$ & $54.7 \%$ & $53.6 \% *$ & $56.4 \%$ \\
\hline Non-member & $43.6 \%$ & $49.2 \% *$ & $45.3 \%$ & $46.4 \% *$ & $47.8 \%$ \\
\hline \multicolumn{6}{|l|}{ Nature of employment } \\
\hline Specific beat & $50.3 \%$ & $42.5 \% *$ & $44.3 \% *$ & $41.0 \% *$ & $20.7 \% *$ \\
\hline Various topics & $49.7 \%$ & $57.5 \% *$ & $55.7 \% *$ & $59.0 \% *$ & $79.3 \% *$ \\
\hline \multicolumn{6}{|l|}{ Rank } \\
\hline \begin{tabular}{l|l} 
Senior/exec. Man. \\
\end{tabular} & $13.1 \%$ & $15.0 \% *$ & $15.8 \% *$ & $24.1 \% *$ & $51.0 \% *$ \\
\hline Junior manager & $12.8 \%$ & $29.6 \% *$ & $33.1 \% *$ & $27.3 \% *$ & $22.0 \% *$ \\
\hline \begin{tabular}{l|l} 
Rank-and-file \\
\end{tabular} & $74.1 \%$ & $55.4 \% *$ & $51.2 \% *$ & $48.6 \% *$ & $27.1 \% *$ \\
\hline \multicolumn{6}{|l|}{ Years working in field } \\
\hline \begin{tabular}{l|l} 
& Mean (std.dev)
\end{tabular} & $18.88(11.17)$ & $13.59(10.21)^{*}$ & $16.18(10.69)^{*}$ & $17.55(11.91)^{*}$ & $22.74(12.03)^{*}$ \\
\hline
\end{tabular}

$* \mathrm{p}<0.05$ when compared to Canadian population

${ }^{1}$ Samples stratified by employment, and should therefore not be used to make inferences about the population 


\section{Political and Social Role Orientations}

Table 2 provides the mean scores for each of the 21 role orientations, grouped by themes.

From a political perspective, our clearest finding concerns the extent to which Canadian journalists are more likely than peers elsewhere to understand themselves as having a strongly monitorial role, which we understand in much the same way as do Christians et al $(2009,137$ 140) . Under this theme heading, the Canadians believe most strongly that they should "report things as they are" (4.92), tell stories about the world (4.31) as detached observers (4.12) as a way to educate the audience (4.62), and provide analysis of current affairs (4.10). Their role is one that provides political information (3.90), and monitors and scrutinizes the conduct of both politics (3.85) and business (3.72). Nearly all these mean scores are significantly higher than those from elsewhere in the world at large, from other developed countries, and from the English-dominant developed countries. However, the comparison with US journalists is more complex; three of that country's mean scores are higher than Canada's, one is lower, and the remainder are similar. It is noteworthy, however, that even though Canadian journalists reported a higher average score for "report things as they are," all comparison groups ranked this item as the most important relative to other role conceptions queried as part of the survey.

The apparent Canadian exceptionalism on monitorial roles is thrown into sharper relief when contrasted to statements that suggest a role that we (again echoing Christians et al, 2009) describe as collaborative. This role encompasses functions such as supporting government policy (1.24) and conveying a positive image of political leadership (1.26). Once again, Canadians are not alone among comparator groups in ranking this role less important than others, but the Canadians scores are exceptionally low when compared with other groups - this time, including the United States. 
Table 2: Perceived roles: average score on scale from 1 (strongly disagree) to 5 (strongly agree)

\begin{tabular}{|c|c|c|c|c|c|}
\hline & $\begin{array}{l}\text { Canada } \\
(\mathrm{N}=352)\end{array}$ & $\begin{array}{c}\text { Global } \\
\text { (excluding } \\
\text { Canada) } \\
(\mathrm{N}=27,215)\end{array}$ & $\begin{array}{c}\text { Other } \\
\text { developed } \\
\text { countries } \\
(\mathrm{N}=14,105)\end{array}$ & $\begin{array}{c}\text { Other } \\
\text { English- } \\
\text { speaking } \\
\text { developed } \\
\text { countries } \\
(\mathrm{N}=2,562)\end{array}$ & $\begin{array}{c}\text { USA } \\
(\mathrm{N}=414)\end{array}$ \\
\hline \multicolumn{6}{|l|}{ Monitorial role } \\
\hline Be a detached observer & 4.12 & $3.97 *$ & 4.13 & 4.06 & 4.09 \\
\hline Report things as they are & 4.82 & $4.49 *$ & $4.57 *$ & $4.64 *$ & 4.82 \\
\hline Provide political information & 3.90 & $3.72 *$ & $3.64 *$ & $3.49 *$ & $4.41 *$ \\
\hline Monitor and scrutinize politics & 3.85 & $3.68 *$ & $3.58 *$ & $3.64 *$ & $4.33 *$ \\
\hline Monitor and scrutinize business & 3.72 & $3.50 *$ & $3.44^{*}$ & 3.59 & $3.89 *$ \\
\hline Provide analysis of current affairs & 4.10 & 4.07 & 4.04 & $3.72 *$ & $3.79 *$ \\
\hline Tell stories about the world & 4.31 & $3.80 *$ & $3.78 *$ & $3.89 *$ & Not asked \\
\hline Educate the audience & 4.62 & $3.89 *$ & $3.71 *$ & $4.23 *$ & 4.55 \\
\hline \multicolumn{6}{|l|}{ Interventionist role } \\
\hline Advocate for social change & 2.91 & $3.49 *$ & 3.04 & 2.92 & 2.72 \\
\hline Influence public opinion & 2.81 & $3.26^{*}$ & 2.82 & $2.67 *$ & $2.40 *$ \\
\hline Set the political agenda & 2.51 & $2.90 *$ & 2.62 & $2.32 *$ & $2.09 *$ \\
\hline Support national development & 2.30 & $3.31 *$ & $2.76^{*}$ & $2.54 *$ & 2.33 \\
\hline Motivate people to participate in politics & 2.93 & $3.13 *$ & 2.90 & $2.58 *$ & $3.29 *$ \\
\hline Be an adversary of the government & 2.04 & $2.49 *$ & $2.36^{*}$ & 2.07 & $2.30 *$ \\
\hline Promote tolerance and cultural diversity & 3.72 & $3.98 *$ & 3.74 & $3.43 *$ & $3.43 *$ \\
\hline \multicolumn{6}{|l|}{ Collaborative role } \\
\hline \begin{tabular}{l|l} 
Support government policy \\
\end{tabular} & 1.24 & $2.08^{*}$ & $1.45^{*}$ & $1.44^{*}$ & $1.49^{*}$ \\
\hline Convey positive image of pol. leaders & 1.26 & $1.99 *$ & $1.46^{*}$ & $1.49 *$ & $1.51 *$ \\
\hline \multicolumn{6}{|l|}{ Accommodative role } \\
\hline \begin{tabular}{l|l} 
Provide entertainment and relaxation \\
\end{tabular} & 2.54 & $3.09 *$ & $2.99 *$ & $3.24 *$ & $2.87 *$ \\
\hline Provide news to attract largest audience & 2.78 & $3.44 *$ & $3.16^{*}$ & $3.43 *$ & $3.52 *$ \\
\hline Provide advice, orientation and direction & 2.62 & $3.35^{*}$ & $3.13^{*}$ & $2.77 *$ & $2.84^{*}$ \\
\hline Let people express their views & 3.88 & 3.90 & $3.73 *$ & 3.82 & $4.21 *$ \\
\hline
\end{tabular}

$* \mathrm{p}<0.05$ when compared to Canadian population

Another consistent difference between the Canadian and all comparator means may be seen in the lower importance that the Canadian respondents placed on accommodative functions [1]. Their mean score on items regarding the importance of providing entertainment and relaxation (2.54), providing news that attracts the largest audience (2.78) and providing advice, orientation and direction for daily life (2.62) were lower than for all other comparator groups. However, when examining more interventionist roles, the pattern is more nuanced. Like journalists in developed countries generally, the Canadians are disinclined to support 
governments or, conversely, to advocate for social change. On the other hand, they support a role of promoting tolerance and diversity more strongly than do others in the English-dominant country group (though still below the world average), and are weaker than others in the Englishspeaking developed group in rejecting the roles of influencing public opinion and setting the political agenda.

\section{Perceived Influences on Journalistic Work}

The extent to which journalists report their professional work being subject to various kinds of influences is illustrated in Table 3. These results show that Canadian journalists profess strikingly low levels of influence compared to journalists in other countries. Canadian journalists tended to report "little" to "no" influence upon their work by politicians, government officials, pressure groups, and business representatives, with mean scores lower than for all other comparator groupings, including the United States, as are the means for the influence of profit expectations and advertising considerations.

In general, Canadian journalists report that political, economic, organizational and social factors have relatively little influence on their professional work. The mean scores even for acknowledged influences in these categories, such as editorial policy (3.19) and personal values and beliefs (3.22), tend only slightly to exceed the midpoint (3.0) between agreement and disagreement with the existence of influence, and remain lower than in all other countries. Unsurprisingly, greater influence is acknowledged for supervisors and higher editors, but even these scores are lower than in comparator countries. 
Table 3: Perceived influences: average score on scale from 1 (strongly disagree) to 5 (strongly agree)

\begin{tabular}{|c|c|c|c|c|c|}
\hline & $\begin{array}{l}\text { Canada } \\
(\mathrm{N}=352)\end{array}$ & $\begin{array}{c}\text { Global } \\
\text { (excluding } \\
\text { Canada) } \\
(\mathrm{N}=27,215)\end{array}$ & $\begin{array}{c}\text { Other } \\
\text { developed } \\
\text { countries } \\
(\mathrm{N}=14,105)\end{array}$ & $\begin{array}{l}\text { Other English- } \\
\text { speaking } \\
\text { developed } \\
\text { countries } \\
(\mathrm{N}=2,562)\end{array}$ & $\begin{array}{c}\text { USA } \\
(\mathrm{N}=414)\end{array}$ \\
\hline \multicolumn{6}{|l|}{ Political / government influences } \\
\hline Politicians & $\mathbf{1 . 6 5}$ & $2.22 *$ & $1.85^{*}$ & $2.06^{*}$ & $1.95 *$ \\
\hline Government officials & 1.75 & $2.21 *$ & 1.77 & $2.11 *$ & $2.14 *$ \\
\hline Pressure groups & 1.54 & $2.14 *$ & $1.87^{*}$ & $1.97 *$ & 1.65 \\
\hline Business representatives & 1.64 & $2.16^{*}$ & $1.86^{*}$ & $2.19 *$ & $1.99 *$ \\
\hline Censorship & 1.65 & $2.44 *$ & $1.80 *$ & $2.34 *$ & $2.15^{*}$ \\
\hline Military, police \& state sec. & 1.54 & $2.19 *$ & $1.80 *$ & $2.19 *$ & $2.85 *$ \\
\hline \multicolumn{6}{|l|}{ Organizational influences } \\
\hline Managers of news organizations & 2.66 & $3.05^{*}$ & 2.68 & $2.84^{*}$ & $3.44 *$ \\
\hline Supervisors and higher editors & $\mathbf{3 . 3 5}$ & 3.46 & 3.34 & $3.56^{*}$ & $3.72 *$ \\
\hline Owners of news organizations & 1.77 & $2.82 *$ & $2.31 *$ & $2.33 *$ & $2.64 *$ \\
\hline Editorial policy & 3.19 & $3.59 *$ & $3.45 *$ & $3.70^{*}$ & $3.74 *$ \\
\hline \multicolumn{6}{|l|}{ Procedural influences } \\
\hline Information access & 3.68 & 3.74 & 3.64 & $3.88^{*}$ & $4.01 *$ \\
\hline Journalism ethics & 4.53 & $4.07 *$ & $4.04 *$ & $4.26^{*}$ & 4.59 \\
\hline Media laws and regulation & 3.68 & $3.43 *$ & $3.23 *$ & $3.88^{*}$ & $4.01 *$ \\
\hline Availability of news-gathering resources & 3.71 & $3.58 *$ & $3.56^{*}$ & 3.79 & $3.85 *$ \\
\hline Time limits & 3.78 & 3.71 & 3.75 & $3.89 *$ & 3.82 \\
\hline \multicolumn{6}{|l|}{ Economic influences } \\
\hline Profit expectations & 1.54 & $2.53 *$ & $2.26^{*}$ & $2.16^{*}$ & $1.86^{*}$ \\
\hline Advertising considerations & 1.47 & $2.49 *$ & $2.13 *$ & $2.11 *$ & $1.72 *$ \\
\hline Audience research and data & 2.68 & $3.04 *$ & $2.83 *$ & $3.14 *$ & $3.10 *$ \\
\hline Feedback from the audience & 2.62 & $3.23 *$ & $3.00 *$ & $3.32 *$ & $3.37 *$ \\
\hline Competing news organizations & 2.57 & $2.97 *$ & $2.77 *$ & $3.00 *$ & $2.85^{*}$ \\
\hline \multicolumn{6}{|l|}{ Personal / social } \\
\hline Friends, acquaint., and family & 1.91 & $2.36^{*}$ & $2.22 *$ & $2.24 *$ & $2.21 *$ \\
\hline Colleagues in other media & 2.22 & $2.46^{*}$ & 2.27 & $2.51 *$ & $2.64 *$ \\
\hline Peers on the staff & 2.83 & $2.97 *$ & $2.99 *$ & $3.06^{*}$ & $3.25 *$ \\
\hline Relationships with news sources & 3.11 & 3.20 & 3.13 & $3.33 *$ & 3.22 \\
\hline Personal values and beliefs & 3.22 & $3.61 *$ & $3.60^{*}$ & $3.48^{*}$ & $3.39 *$ \\
\hline Religious considerations & $\mathbf{1 . 3 3}$ & $2.19 *$ & $1.72 *$ & $1.86^{*}$ & Not asked \\
\hline Public relations & 1.87 & $2.47 *$ & $2.23 *$ & $2.40 *$ & 2.00 \\
\hline
\end{tabular}

${ }^{*} \mathrm{p}<0.05$ when compared to Canadian population

Greater degrees of influence are reported for the procedural aspects of Canadian journalists' work, especially ethics (4.53), time limits (3.78) and the availability of news-gathering resources (3.71). With the exception of time constraints, the scores in this group are higher compared to journalists worldwide but still lower than journalists in other English-speaking developed 
countries, including the United States. (The influence of time limits is relatively similar across all groups.) However, all groups report these limitations to be among the strongest in comparison to the other influence sources.

Put together, the findings reported so far suggest both similarity and distinctiveness in the ways that Canadian journalists account for their roles and the influences on their work. Canadian journalists are similar to journalists in other countries insofar as the relative rank-order of many political role conceptions and perceived influences. However, Canadian journalists distinguish themselves in the degree of role-importance and of reported influence. Considerations associated with neutrality and autonomy seem especially distinct, as evidenced by the professed lack of political, organizational, and economic influences and the importance ascribed to monitoring power, accurate reporting, and independent analysis. Contrary to our hypothesis in this respect, a distinctively Canadian emphasis emerged in Canadian journalists' role conceptions and perceived influences, even when compared to countries with similar political, economic and cultural systems. Except in a few isolated respects (to be discussed below), Canadian journalists profess a distinctively detached, critical and autonomous approach to their work oriented to the public interest.

\section{The "Credo" in Historical Perspective}

Our second hypothesis proved as imperfect as the first. We have noted above the impossibility of a firmly quantitative comparison between the role scores reflected in the Pritchard-Sauvageau "credo" and those used in our globally comparable study; nor did the earlier study include any questions relating to influences over professional work. Yet, a 
resemblance may be seen almost at a glance between that turn-of-century monitorial "credo" and the above-described findings from our study, conducted more than 20 years later.

Beyond what immediately meets the eye, this consistency was confirmed using the method of ranking paired variables. The complete list of roles in the panel study of Pritchard et al. was as follows, with the rankings accorded by Canadian journalists overall in 1996 followed by those for 2003, and ties indicated with asterisks: Accurately report the views of public figures $(1,1)$; Get information to the public quickly $\left(2,2^{*}\right)$; Provide analysis and interpretation of complex problems $(3,4)$; Give ordinary people a chance to express views $\left(4^{*}, 5\right)$; Investigate activities of government and public institutions $(4 *, 2 *)$; Discuss public policy while it is being developed $\left(6,6^{*}\right)$; Be skeptical of the actions of public officials $\left(7,6^{*}\right)$; Be skeptical of the actions of business $(8,8)$; Focus on news of interest to the widest possible audience $(9,9)$; Develop the cultural and intellectual interests of the public $(10,10)$; Increase circulation or ratings $(11,11)$; Provide entertainment and relaxation $(12,12)$; Influence public opinion $(13,13)$.

Since providing accurate information was ranked highest among all role values across the entire WJS global sample, it may not be surprising that this same role held top rank among the Canadians in 1996, in 2003, and again in 2014-16. Less predictable is that second place remained constant as well: providing analysis of current affairs. Allowing people to express their views took third place, and scrutinizing business affairs fourth place, both in 1996 and in 2014-16 (although the latter two roles switched in 2003).

Relative to these four roles implying detached reporting and analysis, lesser importance was accorded by both the turn-of-century respondents and by the contemporary Canadian group to influencing public opinion (which ranked last of all roles surveyed in 1996), providing entertainment and relaxation (last among the paired roles in 2014-16), and providing news of 
interest to the widest audience. Thus, contrary to our hypothesis that these roles would rank higher in the current journalistic context, this very preliminary analysis indicates there is some stability in this "credo."

\section{Discussion and Conclusion}

Drawing together the results of our global and historical comparisons, it seems clear that a commitment to accuracy in reporting and analysis, and to social and political neutrality, are a longstanding feature of Canadian journalist's professional self-identification. Even two decades of turbulence in disruptive shifts in the political, economic and social contexts of news-media businesses do not appear to have significantly budged journalists from this position, and attracting, entertaining and influencing audiences remain less important than more politically relevant monitorial roles.

On a global stage, this places the political role conceptions of Canadian journalists firmly in the category of "detached watchdogs," who define themselves by the role of informing citizens about, and monitoring, government and political institutions. (Hanitzsch 2011)However, the Canadian detachment comes with an asterisk: while neither adversarial to government nor inclined to implicate themselves in social change, they do want to promote tolerance and diversity.

Canadian journalists' account of the influences on their practice is consistent with their distinct emphasis on monitorial roles: as compared with other country groupings, they experience themselves as more influenced by procedural and ethical limitations than by political, business or even managerial influences. 
It would be an error to take these findings at face value, as if a person's own account of role or influences is necessarily the last word on the matter. It is unlikely that journalists are quite as "detached" as they might believe. A significant literature points to the role of political and economic elites in shaping news coverage and content (Chomsky and Herman, 1979; Bennett, 1990). Shoemaker and Reese (2014) suggest a much broader range of influences over media content than do journalists themselves including ideology and cultural narratives, which operate more elusively in the selection and formation of news stories, and serve to reproduce particular interests (Hackett and Zhao, 1994).

None of our general findings, therefore, is intended to suggest that assertions of professional role orientations and perceived influences, however sincere, tell the full story of professional orientations in practice. Prima facie, it seems unlikely, for example, that managers and business owners - and the need to attract and satisfy audiences - actually have as little relative influence on news work in practice as is implied by the journalists' conceived autonomy and, in turn, on the preeminence of independent monitorial reporting roles. As Plaisance and Skewes demonstrated (2003), journalists' statements about their values and roles sometimes seem so mutually contradictory as to indicate some ambivalence, particularly about the value of an adversarial stance toward power versus the ideal of neutrality. And, as Voakes found in comparing journalists' choices in hypothetical scenarios to their separate, theoretical ratings of lists of social influences, journalists' ethical choices interact with their own understandings of roles and values in "a dynamic swirl of social factors." (Voakes 1997, 21) Yet, journalists persist in affirming a collective commitment to monitorial rigour; the way they tend to describe factual verification, for instance, has been described as "a prominent, dynamic figure in the stories that journalists tell of their work." (Shapiro et al. 2016, 45) Some might suspect persistent self- 
identifying narratives of this kind as pragmatic elements in an always-embattled profession's self-defining "boundary work." (See Berkowitz and Gutsche 2012; Eldridge 2012.) But it seems more likely, given the above-mentioned social-psychological rewards of moral consistency, that values-narratives will constructively influence both normative professional cultures and journalists' personal, internalized approaches to their work - their ideology of practice.

If Canadian journalists' collective account of their independence and detachment is best understood as a values narrative or, indeed, article of faith, it becomes apt that two highly disruptive decades ago, Pritchard and Sauvageau had already settled on the term "credo" ("I believe") to describe Canadian journalists' collective orientation to the rapid dissemination of accurate information, and analysis of public information and opinion. Like many quasi-religious narratives, this orientation drives an impassioned sense of mission-in this case, a perhaps career-limiting commitment to put the public interest above the interests of news-industry stakeholders.

Understanding the distinctive story that journalists continue to tell themselves about their political role conceptions should therefore prompt new directions of inquiry. How do Canadian journalists' personal characteristics and the organizational attributes of their employers correlate with professional role conceptions? To what extent might journalists' political leanings impact the way they understand their work, or how they portray different types of influences? There are also structural influences to explore. For example, recognizing that the characteristics of an employer organization can influence the role orientations of journalists (Langlois and Sauvageau 1982) suggests a need for further analysis of how role perceptions and norms of practice correlate with working conditions such as union membership, freelance/part-time/full-time status, and permanent or contract employment. Given the likelihood of continued 
transformations in the media and political landscape, we also hope to follow up with the surveyed journalists in this study to examine the degree of stability in their opinions.

Perhaps most important, it is necessary to understand the degree to which, and the manner in which, professional aspirations are reflected in particular choices that journalists make in covering and interpreting political, economic and cultural events, exposing issues warranting political action and policy change, and scrutinizing the effectiveness of democratic institutions. Since we have been describing apparent articles of faith, it may be worth recalling that religious leaders often describe faith as dead unless expressed in works. In the same vein, the next stage of our research will expand our methodology to explore the impact of the Canadian "credo" upon journalists' actions in shaping the content of news, and, by extension, the public's perception of democratic life.

\section{Notes}

[1] Not being politically oriented, our "accommodative" category of role conceptions has no equivalent in the typology of Christians et al., 2009., whereas our "interventionist" category encompasses both the "facilitative" and "radical" roles identified by those authors.

\section{Reference list}

Ahva, Laura, Arjen van Dalen, Jan Fredrik Hovden, Guðbjörg Hildur Kolbeins, Monica Löfgren Nilsson, Morten Skovsgaard, and Jari Väliverronen. 2017. “A Welfare State of Mind?” Journalism Studies 18 (5): 595-613. https://doi.org/10.1080/1461670X.2016.1249005.

Ardıç, Özgül, Jan Anne Annema, and Bert van Wee. 2015. "The Reciprocal Relationship between Policy Debate and Media Coverage: The Case of Road Pricing Policy in the Netherlands."

Transportation Research Part A: Policy and Practice 78 (August): 384-99. https://doi.org/10.1016/j.tra.2015.06.003.

Bardi, Anat, and Shalom H. Schwartz. 2003. "Values and Behavior: Strength and Structure of Relations." Personality and Social Psychology Bulletin 29 (10): 1207-20. https://doi.org/10.1177/0146167203254602. 
Bennett, W. Lance. 1990. "Toward a Theory of Press-state Relations in the United States.” Journal of Communication, 40 (20): 103-25.

Berkowitz, Dan, and Robert E. Gutsche. 2012. "Drawing Lines in the Journalistic Sand: Jon Stewart, Edward R. Murrow, and Memory of News Gone By." Journalism and Mass Communication Quarterly 89 (4): 643-56.

Bonin, Genviève, Filip Dingerkus, Annik Dubied, Stefan Mertens, Heather Rollwagen, Vittoria Sacco, Ivor Shapiro, Olivier Standaert and Vinzenz Wyss. 2017. "Quelle Différence? Language, Culture, and Nationality as Influences on Francophone Journalists' Identity." Journalism Studies 18 (5): 536-554.

Bruns, Axel. 2005. Gatewatching: Collaborative Online News Production. 1 edition. New York: Peter Lang Publishing.

Chomsky, Noam and Edward S. Herman. 1979. The Political Economy of Human Rights. Vol. 1: The Washington connection and Third World fascism. Montreal: Black Rose.

Christians, Clifford G., Theodore L. Glasser, Denis McQuail, Kaarle Nordenstreng, and Robert A. White. 2009. Normative Theories of the Media: Journalism in Democratic Societies. University of Illinois Press

Davis, Aeron. 2007. "Investigating Journalist Influences on Political Issue Agendas at Westminster." Political Communication 24 (2): 181-99. https://doi.org/10.1080/10584600701313033.

Deuze, Mark. 2005. "What is Journalism? Professional Identity and Ideology of Journalists Reconsidered." Journalism 6 (4): 442-464. https://doi.org/10.1177/1464884905056815.

Donsbach, Wolfgang. 2004. "Psychology of News Decisions: Factors behind Journalists' Professional Behavior." Journalism 5 (2): 131-57. https://doi.org/10.1177/146488490452002.

Donsbach, Wolfgang, and Bettina Klett. 1993. "Subjective Objectivity. How Journalists in Four Countries Define a Key Term of Their Profession." Gazette (Leiden, Netherlands) 51 (1): 53-83. https://doi.org/10.1177/001654929305100104.

Drohan, Madelaine. 2016. "Does Serious Journalism Have a Future in Canada?” Ottawa: Public Policy Forum. http://www.ppforum.ca/sites/default/files/PM\%20Fellow_March_11_EN_1.pdf.

Ekos Research Associates. 2018. "Report on Future of Audio and Video Programming in Canada: Surveys and Focus Groups - Findings Report." Canadian Radio-television and Telecommunications Commission (CRTC). http://epe.lac-bac.gc.ca/100/200/301/pwgsctpsgc/por-ef/crtc/2018/051-17-e/report.html.

Eldridge, Scott A. II (2013) “Boundary maintenance and interloper media reaction.” Journalism Studies, $15(1), 1-16$.

Feather, N. T. 1995. "Values, Valences, and Choice: The Influence of Values on the Perceived Attractiveness and Choice of Alternatives." Journal of Personality and Social Psychology; Washington 68 (6): 1135.

Feather, Norman T. 1988. "Values, Valences, and Course Enrollment: Testing the Role of Personal Values within an Expectancy-Valence Framework." Journal of Educational Psychology 80 (3): 381-91. https://doi.org/10.1037/0022-0663.80.3.381.

Fry, Hedy. 2017. "Disruption: Change and Churning in Canada's Media Landscape." Ottawa: Standing Committee on Canadian Heritage, House of Commons. http://www.ourcommons.ca/DocumentViewer/en/42-1/CHPC/report-6/.

Golding, Peter and Philip Ross Courtney Elliott. 1979. Making the News. London: Longman.

Government of Canada. 2018. "Fall Economic Statement." November 21, 2018. https://www.budget.gc.ca/feseea/2018/docs/statement-enonce/chap02en.html\#s2.

Greenspon, Edward. 2017. "The Shattered Mirror: News, Democracy and Trust in the Digital Age | Public Policy Forum.” February 2, 2017. http://www.ppforum.ca/publications/shattered-mirrornews-democracy-and-trust-digital-age.

Hackett, Robert A. 2006. "Is Peace Journalism Possible? Three Frameworks for Assessing Structure and Agency in News Media” Conflict \& Communication Online 5 (2): 13. 
Hackett, Robert A. and Yuezhi Zhao. 1994. "Challenging a master narrative: Peace protest and opinion/editorial discourse in the US press during the Gulf War." Discourse \& Society 54 (4): 509-41.

Hallin, Daniel C., and Paolo Mancini. 2004. Comparing Media Systems: Three Models of Media and Politics. New York: Cambridge University Press.

Hanitzsch, Thomas. 2007. "Deconstructing Journalism Culture: Toward a Universal Theory." Communication Theory 17 (4): 367-85.

- 2011. "Populist Disseminators, Detached Watchdogs, Critical Change Agents and Opportunist Facilitators: Professional Milieus, the Journalistic Field and Autonomy in 18 Countries." International Communication Gazette 73 (6): 477-94. https://doi.org/10.1177/1748048511412279.

Hanitzsch, Thomas, Maria Anikina, Rosa Berganza, Incilay Cangoz, Mihai Coman, Basyouni Hamada, Folker Hanusch, et al. 2010. "Modeling Perceived Influences on Journalism: Evidence from a Cross-National Survey of Journalists.” Journalism and Mass Communication Quarterly 87 (1): $5-22$.

Hanitzsch, Thomas, Folker Hanusch, Claudia Mellado, Maria Anikina, Rosa Berganza, Incilay Cangoz, Mihai Coman, et al. 2011. "Mapping Journalism Cultures across Nations." Journalism Studies 12 (3): 273-93. https://doi.org/10.1080/1461670X.2010.512502.

Hanusch, Folker. 2009. “A Product of Their Culture.” International Communication Gazette 71 (7): 613 26. https://doi.org/10.1177/1748048509341895.

Kim, Kihan, and Maxwell McCombs. 2007. "News Story Descriptions and the Public's Opinions of Political Candidates." Journalism \& Mass Communication Quarterly 84 (2): 299-314. https://doi.org/10.1177/107769900708400207.

Langlois, Simon, and Florian Sauvageau. 1982. "Les journalistes des quotidiens québécois et leur métier." Politique 1 (2): 5-39. https://doi.org/10.7202/040400ar.

Lauerer, Corinna and Thomas Hanitzsch. Forthcoming. "Surveying Journalists: The Methological Framework." In Thomas Hanitzsch, Folker Hanusch, Jyotika Ramaprasad and Arnold S. de Beer (eds.), Worlds of Journalism: Comparing Journalistic Cultures across the Globe. New York: Columbia University Press.

Lee, Eun-Ju, and Edson C. Tandoc. 2017. "When News Meets the Audience: How Audience Feedback Online Affects News Production and Consumption." Human Communication Research 43 (4): 436-49. https://doi.org/10.1111/hcre.12123.

McCombs, Maxwell. 2017. Contemporary Public Opinion: Issues and the News. Routledge.

Melenhorst, Lotte. 2015. “The Media's Role in Lawmaking: A Case Study Analysis.” The International Journal of Press/Politics 20 (3): 297-316. https://doi.org/10.1177/1940161215581924.

Merritt, Davis. 1995. "Public Journalism - Defining a Democratic Art." Media Studies Journal, 9 (3):125-132.

Milliband, Ralph. 1969. The State in Capitalist Society: The Analysis of the Western System of Power. London, UK: Quartet Books.

Mitchell, Amy, Katie Simmons, Katerina Eva Matsa, and Laura Silver. 2018. "Publics Globally Want Unbiased News Coverage, but Are Divided on Whether Their News Media Deliver." Pew Research Center's Global Attitudes Project. January 11, 2018. http://www.pewglobal.org/2018/01/11/publics-globally-want-unbiased-news-coverage-but-aredivided-on-whether-their-news-media-deliver/.

Newman, Nic. 2018. "Digital News Report, 2018.” Oxford, UK: Reuters Institute for the Study of Journalism, University of Oxford. http://www.digitalnewsreport.org/survey/2018/overview-keyfindings-2018/.

Peer, Limor, and Thomas B. Ksiazek. 2011. "YouTube and the Challenge to Journalism." Journalism Studies 12 (1): 45-63. 
Plaisance, Patrick Lee, and Elizabeth A. Skewes. 2003. "Personal and Professional Dimensions of News Work: Exploring the Link between Journalists' Values and Roles." Journalism \& Mass Communication Quarterly 80 (4): 833-48. https://doi.org/10.1177/107769900308000406.

Preston, Paschal. 2008. Making the News: Journalism and News Cultures in Europe. London: Routledge.

Pritchard, David, Paul R. Brewer, and Florian Sauvageau. 2005. "Changes in Canadian Journalists' Views about the Social and Political Roles of the News Media: A Panel Study, 1996-2003." Canadian Journal of Political Science 38 (2): 287-306.

Pritchard, David, and Florian Sauvageau. 1999. Les Journalistes Canadien: Un Portrait de Fin de Siècle. Sainte-Foy, QC: Les Presses de l'Université Laval.

Rokeach, Milton. 1973. The Nature of Human Values. Free Press.

Schudson, Michael. 2002. The Sociology of News. Contemporary Societies. New York: Norton.

Shapiro, Ivor, Colette Brin, Philippa Spoel and Lee Marshall. 2016. Images of Essence: Journalists Discourse on the Professional Discipline of Verification." Canadian Journal of Communication 41 (1): 37-48.

Shoemaker, Pamela J., and Stephen D. Reese. 2014. Mediating the Message in the 21st Century: A Media Sociology Perspective. Third edition. New York: Routledge.

Shoemaker, Pamela J., and Timothy Vos. 2008. Gatekeeping Theory. Florence, United States: Routledge.

Siebert, Fred, Theodore Bernard Peterson, Theodore Peterson, and Wilbur Schramm. 1956. Four Theories of the Press: The Authoritarian, Libertarian, Social Responsibility, and Soviet Communist Concepts of What the Press Should Be and Do. University of Illinois Press.

Soderlund, Walter C., Colette Brin, Lydia Miljan, and Kai Hildebrandt. 2012. Cross-Media Ownership and Democratic Practice in Canada: Content-Sharing and the Impact of New Media. University of Alberta.

Strömbäck, Jesper. 2008. "Four Phases of Mediatization: An Analysis of the Mediatization of Politics." The International Journal of Press/Politics 13 (3): 228-46. https://doi.org/10.1177/1940161208319097.

Tan, Yue, and David H. Weaver. 2009. "Local Media, Public Opinion, and State Legislative Policies: Agenda Setting at the State Level." The International Journal of Press/Politics 14 (4): 454-76. https://doi.org/10.1177/1940161209336225.

Tandoc, Edson C (Jr.), and Ryan J. Thomas. 2015. “The Ethics of Web Analytics.” Digital Journalism 3 (2): 243-58. https://doi.org/10.1080/21670811.2014.909122.

Tandoc, Edson C. 2014. "Journalism Is Twerking? How Web Analytics Is Changing the Process of Gatekeeping.” New Media \& Society 16 (4): 559-75. https://doi.org/10.1177/1461444814530541.

Thompson, Derek. 2014. "What the Death of Homepages Means for the Future of News." The Atlantic, May 15, 2014. http://www.theatlantic.com/business/archive/2014/05/what-the-death-thehomepage-means-for-news/370997/.

Tuchman, Gaye. 1978. Making News: A Study in the Construction of Reality. New York: Free Press.

Voakes, Paul S. 1997. "Social Influences on Journalists' Decision Making in Ethical Situations." Journal of Mass Media Ethics 12 (1): 18-35.

$\mathrm{Vu}$, Hong Tien. 2014. "The Online Audience as Gatekeeper: The Influence of Reader Metrics on News Editorial Selection.” Journalism 15 (8): 1094-1110. https://doi.org/10.1177/1464884913504259.

Weaver, David H., and Lars Willnat. 2012. The Global Journalist in the 21 st Century. Routledge Communication Series. New York: Routledge.

Welbers, Kasper, Wouter van Atteveldt, Jan Kleinnijenhuis, Nel Ruigrok, and Joep Schaper. 2016. "News Selection Criteria in the Digital Age: Professional Norms versus Online Audience Metrics." Journalism 17 (8): 1037-53. https://doi.org/10.1177/1464884915595474.

Wolfe, Michelle, Bryan D. Jones, and Frank R. Baumgartner. 2013. "A Failure to Communicate: Agenda Setting in Media and Policy Studies." Political Communication 30 (2): 175-92. https://doi.org/10.1080/10584609.2012.737419. 